\title{
Morphological features and thermal and mechanical response in segmented polyurethane elastomers based on mixtures of isocyanates
}

\author{
Cristina Prisacariu, Elena Scortanu, Iuliana Stoica, Bogdan Agapie and Virgil Barboiu
}

\begin{abstract}
A family of segmented polyurethane elastomers (SPUs) was synthesized. Hard segments were chosen to be generated from two isocyanates: the rigid 4,4-diphenylmethane diisocyanate (MDI) and the flexible 4,4-dibenzyl diisocyanate (DBDI), alone or as mixtures. A polyester soft segment polyethylene adipate of molar mass $2000 \mathrm{~g} \mathrm{~mol}^{-1}$ and a small molecule chain-extender diol, ethylene glycol, were used. Hard segment fraction was maintained at $\sim 40 \%$. The structure-property relationship of SPUs was investigated using several characterization techniques. Morphological features such as interdomains of the soft and hard segments were identified by means of atomic force microscopy. The thermal and mechanical behavior was evaluated by using dynamic mechanical analysis, differential scanning calorimetry and uniaxial tensile tests. Structural changes induced by varying the type and the number of isocyanates and the order of their introduction were also followed by using wide-angle X-ray. Materials with hard segments based on the single diisocyanate DBDI were observed to crystallize. Crystallinity was strongly reduced when DBDI was mixed with MDI. Improvement in elastomeric properties was obtained when both diisocyanates were included and reacted together in a random manner.
\end{abstract}

Polymer Journal (2011) 43, 613-620; doi:10.1038/pj.2011.23; published online 6 April 2011

Keywords: mixtures of diisocyanates; morphology; segmented polyurethanes; thermal and mechanical behavior

\section{INTRODUCTION}

Polyurethane polymers form a class of materials with unique versatility. They are all characterized by the presence of the urethane link - $\mathrm{NH}-\mathrm{CO}-\mathrm{O}-$ in the macromolecular backbone, and formed by reaction between isocyanates and polyols; however, materials with wide variations in physical properties are possible by varying the choice of these ingredients. An important subgroup is the polyurethane elastomers, in which at least one ingredient has a glass transition below room temperature. ${ }^{1-8}$ In the segmented polyurethane elastomers (SPUs) studied in the present work, molecules consist of alternating flexible (soft) and relatively rigid (hard) segments. Phase segregation occurs during and following polymerization, to produce an elastomeric matrix of the soft segments containing rigid inclusions (of size scale $10-100 \mathrm{~nm}$ ) formed by association of the hard segments. ${ }^{1-3}$ The structure is therefore that of a polymer matrix microcomposite.

The present work is part of a wider study ${ }^{8-12}$ of the effects on constitutive response of systematically varying the key structural variables: hard segment, soft segment and crosslinking. Such variations in composition lead to significant changes in the key mechanical properties of the elastomer, such as stiffness, strain recovery and strain energy recovery.
In our previous works, we produced a wide range of segmented SPUs obtained with single diisocyanates, in which the chemical ingredients were varied. A systematic investigation was conducted of the correlation between structural features (phase segregation and degree of crystallinity) and the cyclic tensile responses of SPUs obtained with single diisocyanates, in which the diisocyanates, macrodiols and chain extenders were varied. It has been shown already that these chemical changes lead to varying degrees of phase segregation and crystallization in the hard segment, particularly when using 4 , 4-dibenzyl diisocyanate (DBDI) that displays a variable geometry.

We have studied the mechanical properties of a series of SPUs derived from single diisocyanates under cyclic straining and found trends in the cyclic stress-strain response, including a systematic variation of the degree of Mullins effect with varying chemical structure. ${ }^{9}$

As a general observation for the materials studied, on first loading, the tensile modulus and the strain energy recovery on cycling (hysteresis) at 300\% strain were found to increase significantly with increase in hard phase degree of crystallinity, achieved primarily by use of DBDI, with ethylene glycol (EG) or butylene glycol as chain extenders, instead of the conventional rigid 4,4-diphenylmethane diisocyanate (MDI) as diisocyanate. As shown, the origin of these

The Romanian Academy's Institute of Macromolecular Chemistry 'Petru Poni', Aleea Grigore Ghica Voda, lasi, Romania

Correspondence: Dr C Prisacariu, Department of Physics and Structure of Polymers, The Romanian Academy's Institute of Macromolecular Chemistry Petru Poni, Aleea Grigore Ghica Voda, Nr. 41 A, lasi 700487, Romania.

E-mail: crispris@icmpp.ro

Received 7 October 2010; revised 23 February 2011; accepted 24 February 2011; published online 6 April 2011 
effects was intimately related to the nanoscale structure of the elastomers through the degree of phase segregation and the size and perfection of the hard domains.

The aim of the specific work reported here was to investigate the role of hard segment structure. Two hard segment types were compared on the basis of the two diisocyanates MDI and DBDI, alone or as mixtures of them. The former is widely used in commercial SPUs. The latter is a novel diisocyanate, also now available commercially, first synthesized in our (Romanian) laboratory. ${ }^{8-12}$ Rotation around the central $-\mathrm{CH}_{2}-\mathrm{CH}_{2}-$ bond in DBDI allows alignment of successive aromatic rings thus favoring the tendency of crystallization which involves the DBDI hard phase. ${ }^{9-12}$

The chain extender EG and the soft segment macrodiol polyethylene adipate (PEA) of molar mass $2000 \mathrm{~g} \mathrm{~mol}^{-1}$ were considered. PEA was chosen because this polyester is well known to possess a greater affinity for the diisocyanates through hydrogen bonding to its ester groups and hence is more miscible with the diisocyanates and phase segregation is expected to be less pronounced, ${ }^{2,6}$ whereas polyethers such as poly(oxytetramethylene) (PTMO) are well known to promote phase separation from the diisocyanates. The SPUs were prepared with no excess of isocyanate (NCO) groups, yielding isocyanate index $I=100,{ }^{2,9}$ which means that they are truly thermoplastic. They do not have the potential for further reaction with ambient humidity to produce chain lengthening and allophanate crosslinking, seen in similar polymers but with excess isocyanate groups (for example, $I=110){ }^{9}$

The changes in crystallinity occurring in SPUs based on mixtures of DI were followed as compared with those observed in SPUs based on MDI or DBDI alone. Morphological features of materials based on single diisocyanates (MDI or DBDI), such as interdomains of soft and hard segments, were identified by means of atomic force microscopy (AFM). Structural changes induced by varying the type and the number of isocyanates and the order of their introduction were also followed by using wide-angle X-ray (WAXS). Dynamic mechanical analysis (DMA) and differential scanning calorimetry (DSC) were used to follow the changes that were brought about by changing the type and the number of isocyanates (one or two DI), and the order of their introduction in the material synthesis.

\section{MATERIALS AND METHODS}

\section{Materials}

Commercial products such as the macrodiol PEA, MDI (Aldrich, Aldrich Chemical, St Louis, MO, USA), the flexible DBDI (produced in the Romanian laboratory) and EG (Aldrich) were used, which were purified by distillation at $0.1 \mathrm{~mm} \mathrm{Hg}(\mathrm{MDI})$, or by recrystallization from dry cyclohexane (DBDI).

(a) SPUs derived from a single diisocyanate $\left(\mathrm{SPU}_{4}\right.$ with $\mathrm{DBDI}$ and $\mathrm{SPU}_{5}$ with MDI; Table 1) were obtained as follows: $100 \mathrm{~g}(0.05 \mathrm{~mol})$ of PEA was dehydrated under mixing at $110^{\circ} \mathrm{C}$ and under vacuum $(<1 \mathrm{~mm} \mathrm{Hg})$ for $2 \mathrm{~h}$. A quantity of $52.8 \mathrm{~g}(0.2 \mathrm{~mol})$ of DBDI for the $\mathrm{SPU}_{4}$ type or $50 \mathrm{~g}$ $(0.2 \mathrm{~mol})$ of MDI in the case of $\mathrm{SPU}_{5}$ type of elastomer was added at once, under intense mixing, to the anhydrous macrodiol and vacuum was restored. After $30 \mathrm{~min}$ of mixing under vacuum at $100^{\circ} \mathrm{C}$, the temperature was reduced to $90^{\circ} \mathrm{C}$ and vacuum was removed. This yielded a prepolymer with final isocyanic NCO groups in a mixture with the excess of isocyanate. Next, 9.295-g $(0.1086 \mathrm{~mol})$ EG was added at once under rapid stirring. The mixing was continued for maximum 30-40 s. The 'pot life' of the mixture was between 3 and $10 \mathrm{~min}$, depending on the SPU structure. During this time, the liquid mixture was cast onto closed teflonated moldings preheated at $90^{\circ} \mathrm{C}$. For the cure process, the closed moldings were maintained after casting at $110^{\circ} \mathrm{C}$ for $24 \mathrm{~h}$. After a further duration of $24 \mathrm{~h}$ at room temperature, the polymeric sheets representing an active PU oligomer with NCO final groups were demoulded. SPU sheets of $0.3-\mathrm{mm}$ thickness were obtained. (b) Copolyurethane elastomers from two diisocyanates that were randomly distributed $\left(\mathrm{SPU}_{1}\right)$ were synthesized starting from PEA. In the prepolymer synthesis, a melt mixture was used: $26.4 \mathrm{~g}(0.1 \mathrm{~mol})$ of DBDI with $25 \mathrm{~g}(0.1 \mathrm{~mol})$ of MDI, which was introduced in the anhydrous polyol at once. The remaining synthesis steps-the chain extension, curing and postcuring-were performed as in the case of general procedure (A).

(c) Copolyurethane elastomers from two diisocyanates with selective diisocyanate distribution $\left(\mathrm{SPU}_{2}\right.$ and $\left.\mathrm{SPU}_{3}\right)$ were obtained by a prepolymer synthesis in two steps. The first prepolymer based on DBDI corresponding to the $\mathrm{SPU}_{2}$ material was obtained by adding in the first step $26.4 \mathrm{~g}$ $(0.1 \mathrm{~mol})$ of DBDI in $100 \mathrm{~g}(0.05 \mathrm{~mol})$ of anhydrous macrodiol PEA, under similar conditions as that for the synthesis of the single prepolymer step technique as mentioned at point (A). Into the prepolymer obtained, $25 \mathrm{~g}(0.1 \mathrm{~mol})$ of MDI was dissolved. After $30 \mathrm{~min}$ of mixing, the remaining synthesis steps-chain extension, cure and postcure process-were performed as in case of point (A). The synthesis of the $\mathrm{SPU}_{3}$ polymer also involved a two-step prepolymer synthesis similar to material $\mathrm{SPU}_{2}$, with the only difference being that the first introduced isocyanate was $0.1 \mathrm{~mol}$ of MDI, followed by dissolution of $0.1 \mathrm{~mol}$ of DBDI in the prepolymer. The following synthesis steps - the chain extension, curing and postcuring were again performed as in the case of general procedure (A).

In all cases, the prepolymer obtained from the reaction between macrodiol and diisocyanate was reacted with EG in a quantity calculated such that there should remain theoretically no excess of unreacted NCO groups. This corresponds to an isocyanate index $I=100 \times[\mathrm{NCO}] /\left([\mathrm{OH}]_{\mathrm{M}}+[\mathrm{OH}]_{\mathrm{CE}}\right)=100$.

\section{Test methods}

DMA measurements were recorded with the Gabo Qualimeter Eplexor 150N (Gabo Qualimeter, Martin-Luther Universitat, Halle-Wittenberg, Germany). The samples were tested in tensile mode with a starting distance between the clamps of $45 \mathrm{~mm}$. The cross-section area of the specimen was $5 \mathrm{~mm} \times 1-2 \mathrm{~mm}$. The samples were placed in the temperature chamber and cooled down to the starting temperature of $-140{ }^{\circ} \mathrm{C}$. The cooling conditions were as follows: at room temperature of $-60^{\circ} \mathrm{C}$ the cooling rate was $10 \mathrm{~K} \mathrm{~min}^{-1}$, at $-60^{\circ} \mathrm{C}$ to $-120{ }^{\circ} \mathrm{C}$ the cooling rate was $3.5 \mathrm{~K} \mathrm{~min}^{-1}$ and at -120 to $-140{ }^{\circ} \mathrm{C}$ the cooling rate was $2 \mathrm{~K} \mathrm{~min}^{-1}$. The DMA tests started at $-140^{\circ} \mathrm{C}$ and the complex modulus $\mathrm{E}^{\star}$, storage modulus $\mathrm{E}^{\prime}$, loss modulus $\mathrm{E}^{\prime}$ and the loss factor $\tan \delta$ were measured as functions of temperature at a heating rate of $1 \mathrm{~K} \mathrm{~min}^{-1}$. The instrument was operated with controlled sinusoidal force with a frequency of $1 \mathrm{~Hz}$.

DSC measurements were recorded with a Mettler Toledo instrument DSC 820 (Mettler Toledo, Martin-Luther Universitat, Halle-Wittenberg, Germany), with a heating rate of 20 and $40 \mathrm{~K} \mathrm{~min}^{-1}$.

AFM measurements to investigate the morphology of SPUs, we have chosen to analyze the internal cross-section surfaces instead of normal sample surfaces because of several reasons, one of them being rather possible contamination of the last ones. Therefore, the surfaces of interest were obtained by fracturing films frozen in liquid nitrogen.

The measurements were performed at room temperature $\left(22-24^{\circ} \mathrm{C}\right)$ by using a Solver PRO-M (NT-MDT Co., Zelenograd, Moscow, Russia) setup. The last version of the NT-MDT NOVA software was used for image acquisition and analysis. Topographic and phase images, obtained over an area

\section{Table 1 Compositions of the family of SPUs}

\begin{tabular}{lccccc}
\hline & & \multicolumn{4}{c}{ SPUs composition } \\
\cline { 3 - 6 } & & Moles of & Moles of & Moles of & Moles of \\
Recipe & SPU structure & $P E A$ & MDI & DBDI & EG \\
\hline $\mathrm{SPU}_{1}$ & EG-PEA-(DBDI-MDI) & 1 & 2 & 2 & 3 \\
$\mathrm{SPU}_{2}$ & EG-(PEA-DBDI)-MDI & 1 & 2 & 2 & 3 \\
$\mathrm{SPU}_{3}$ & EG-(PEA-MDI)-DBDI & 1 & 2 & 2 & 3 \\
$\mathrm{SPU}_{4}$ & EG-PEA-DBDI & 1 & 0 & 4 & 3
\end{tabular}

Abbreviations: DBDI, 4,4-dibenzyl diisocyanate; EG, ethylene glycol; MDI, 4,4-diphenylmethane diisocyanate; PEA, polyethylene adipate; SPU, segmented polyurethane elastomer. 
of $40 \times 40 \mu \mathrm{m}$ for each sample, were recorded using AFM tapping mode in which the cantilever force was controlled to be strong enough to reveal surface details and yet weak enough to avoid the sample damage. A rectangular silicon cantilever NSG10 with a typical force constant of $11.8 \mathrm{~N} \mathrm{~m}^{-1}$ and $287-\mathrm{KHz}$ oscillation frequency was used. Its tip curvature radius and height were $10 \mathrm{~nm}$ and $14-16 \mu \mathrm{m}$, respectively.

The surface textures were characterized in terms of roughness parameters, such as average height $\left(H_{\mathrm{a}}\right)$, root mean square roughness $\left(S_{\mathrm{q}}\right)$ and normalized surface height (NSH).

As it will be shown further, the surfaces investigated were too uneven to allow a valid interpretation of the phase contrast images; therefore, these images are neglected in the present discussion. Such a situation of non-application seems to be characteristic for cross-sections because the AFM phase images from external surfaces seem to be useful.

WAXS scattering patterns were collected using an URD 63 diffractometer (FPM-Seifert, Polymer Service GmbH Merseburg, Merseburg, Germany), which was equipped with a scintillation detector. Ni-filtered $\mathrm{Cu} \mathrm{K \alpha}$ radiation of wavelength $1.5418 \AA$ was used, and the machine was operated in transmission mode. The counting time and the angular increment in data collection were $5 \mathrm{~s}$ and $0.05^{\circ}(2 \theta)$, respectively.

Mechanical tests: the polymers in the form of films, prepared as described above, were subjected to uniaxial tensile tests at constant nominal strain rate. In addition, to investigate mechanical hysteresis, cyclic tensile tests were carried out, cycling between a fixed strain limit and zero load, using a constant nominal strain rate of magnitude $0.03 \mathrm{~s}^{-1}$. Test specimens were cut from films, using dimensions given in ASTM D1708; that is, a dumbbell-shaped specimen with a length of $53 \mathrm{~mm}$ between shoulders, a gauge length of $20 \mathrm{~mm}$ (on which the strain was measured), a width of $5.8 \mathrm{~mm}$ and a thickness of $0.3 \mathrm{~mm}$. The stress-strain data on these specimens presented here were obtained using an Instron 4204 Testing Machine or Schopper MZ Gip Testing Machine, at room temperature $\left(\mathrm{T} \approx 25^{\circ} \mathrm{C}\right)$. Strain was measured manually from the movement of fiducial marks or obtained from grip displacement, after using video images of the gauge length to correct for non-uniform strain outside the gauge length.

\section{RESULTS AND DISCUSSION}

\section{DMA and DSC results}

Depending on the type of synthesis and PU structure, significant differences of the storage modulus (E'), and consequently differences in softening, were found. The glass transition temperature depends on the mobility of the macromolecular chain. $\mathrm{SPU}_{4}$ derived from the single DBDI type of diisocyanate displayed a higher tendency to crystallize. The DMA results are presented in Figures 1-5. The DMA measurements have shown that the storage modulus E' in the temperature range above the glass transition region was the highest for the DBDI-based $\mathrm{SPU}_{4}$ of the type PEA-DBDI-EG, in which only a single type of isocyanate (DBDI) was used in the material synthesis.

This is because of the higher content of DBDI-based hard segments with a coplanar packing. ${ }^{9}$ For the series of elastomers, the glass transition temperatures as defined by the maximum of the loss factor at $f=1 \mathrm{~Hz}$ was found to range from -27 to $-11^{\circ} \mathrm{C}$, the lowest $T_{\mathrm{G}}$ value corresponding to $\mathrm{SPU}_{4}$ (EG-PEA-DBDI), $-27^{\circ} \mathrm{C}$, which displays a variable geometry. The glass transition temperatures are shown in Table 2.

The above results are in agreement with the results from WAXS. ${ }^{13}$ $\mathrm{SPU}_{4}$, which displays a $50 \%$ degree of crystallinity, has the lowest value of loss factor at $T_{\mathrm{G}}$ and the highest modulus above $T_{\mathrm{G}}$. $\mathrm{SPU}_{3}$ and $\mathrm{SPU}_{4}$ melt and degrade at a temperature above $250{ }^{\circ} \mathrm{C}$ in DSC.

As seen in Figures 3 and 4, $\mathrm{SPU}_{4}$ based on DBDI alone, displays the highest thermal stability with two pronounced endotherm maxima occurring at $310-315^{\circ} \mathrm{C}$. In the case of material $\mathrm{SPU}_{3}$ based on mixtures of DI, in which MDI was the first isocyanate to be reacted with PEA, a decrease in the polymer stability is apparent: two large maxima are found situated at temperatures below $300^{\circ} \mathrm{C}$, for example, at 290 and $295^{\circ} \mathrm{C}$, respectively. This is due to the substitution of DBDI

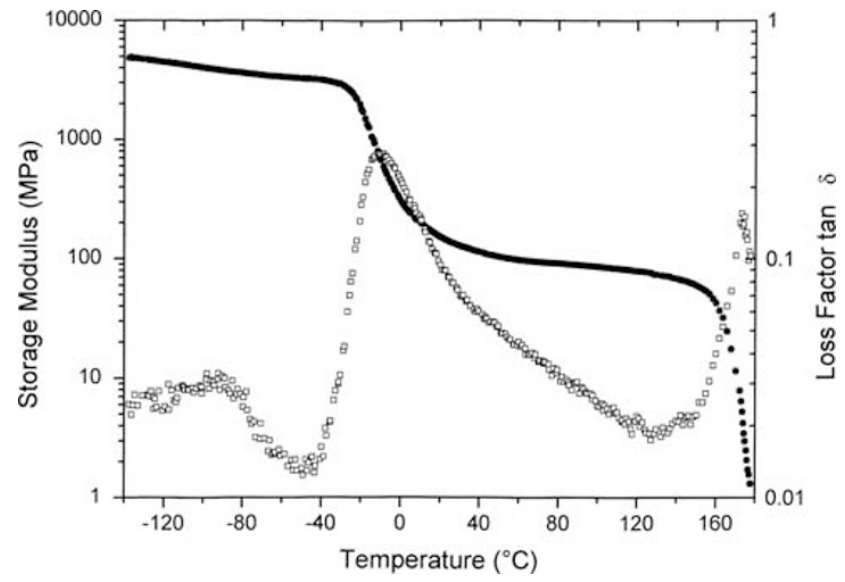

Figure 1 Storage modulus $\mathrm{E}^{\prime}$ and loss factor $\tan \delta$ as a function of temperature for material $\mathrm{SPU}_{1}$ listed in Table 1: $(\bullet)$, storage modulus (E'); $(\bigcirc), \tan \delta$. SPU, segmented polyurethane elastomer.

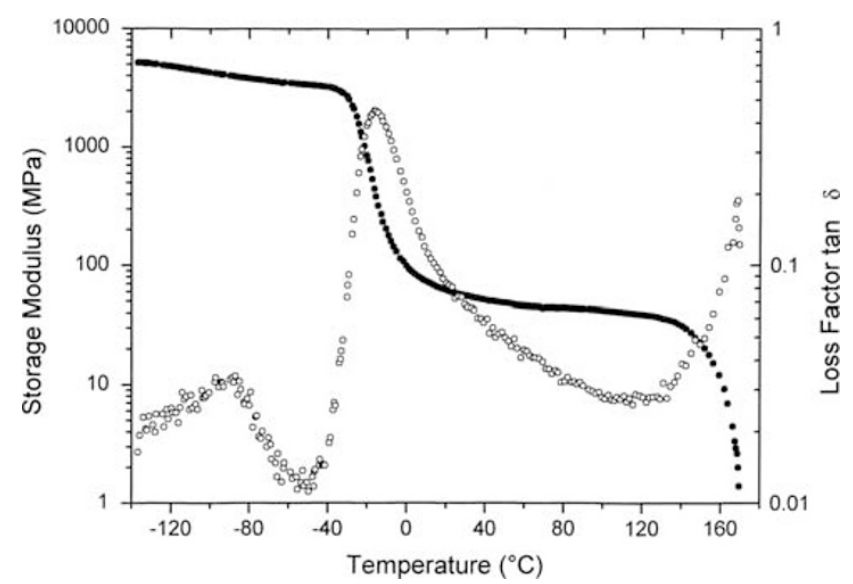

Figure 2 Same as in Figure 1 but for material $\mathrm{SPU}_{2}:(\bullet)$, storage modulus $\left(E^{\prime}\right) ;(O)$, tan $\delta$. SPU, segmented polyurethane elastomer.

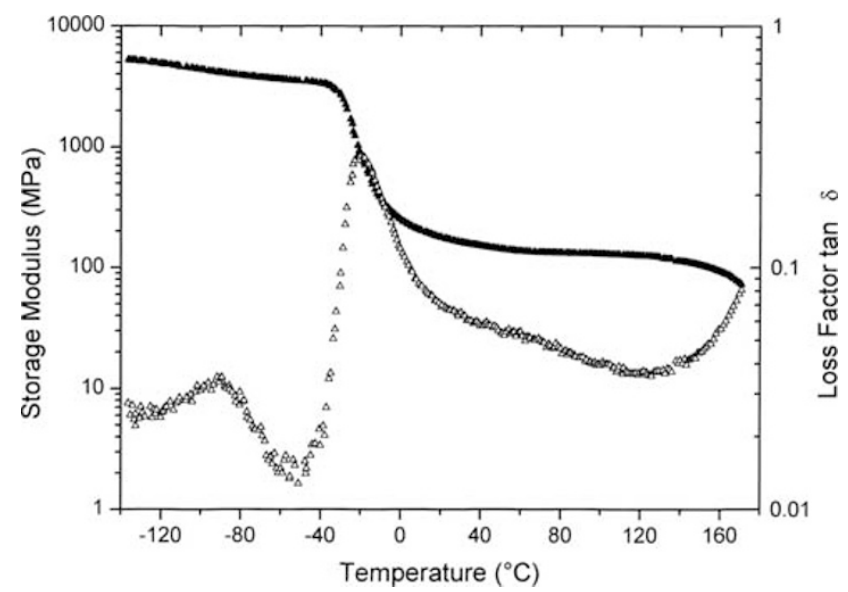

Figure 3 Same as in Figure 1 but for material $\mathrm{SPU}_{3}:(\boldsymbol{\Delta})$, storage modulus $\left(E^{\prime}\right) ;(\triangle), \tan \delta$. SPU, segmented polyurethane elastomer.

by MDI. Previous work has also shown a tendency for the polymer network ordination and crystallinity to decrease ${ }^{3,4}$ (Figures 6 and 7).

In the case of $\mathrm{SPU}_{3}$, with decreased crystallinity and intermolecular interactions, there is even a tendency of the soft segments to crystallize. This is evidenced by the appearance of an endotherm maximum 


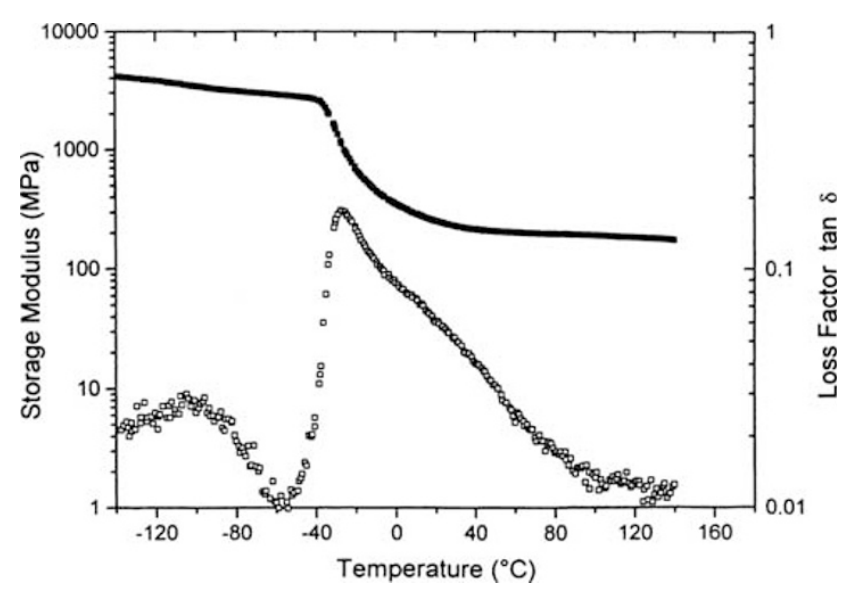

Figure 4 Same as in Figure 1 but for materials $\mathrm{SPU}_{4}:(\bullet)$, storage modulus $\left(E^{\prime}\right) ;(O), \tan \delta$. SPU, segmented polyurethane elastomer.

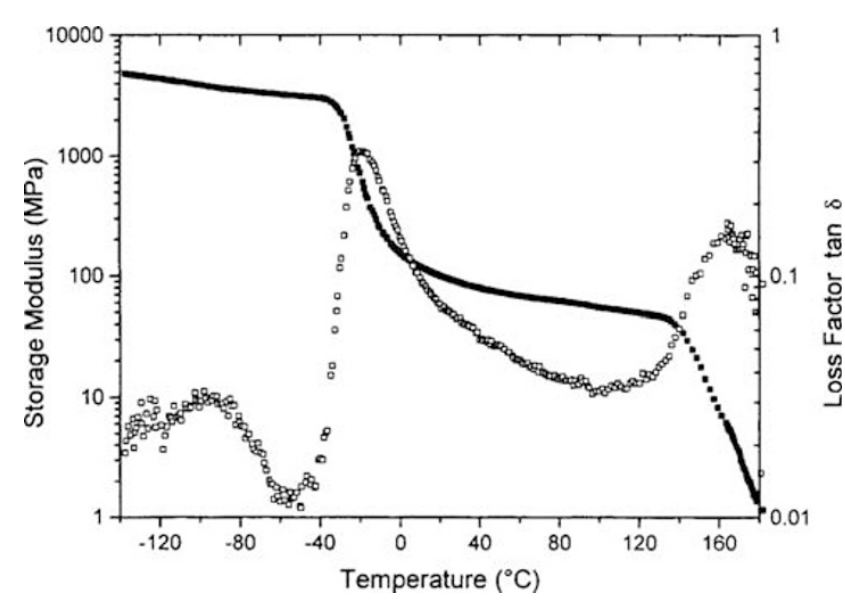

Figure 5 Same as in Figure 1 but for materials $\operatorname{SPU}_{5}:(\bullet)$, storage modulus $\left(E^{\prime}\right) ;(O), \tan \delta$. SPU, segmented polyurethane elastomer.

Table 2 DMA measurements values

\begin{tabular}{lccccc}
\hline & $S P U_{1}$ & $S P U_{2}$ & $S P U_{3}$ & $S P U_{4}$ & $S P U_{5}$ \\
\hline$T_{\mathrm{G}},{ }^{\circ} \mathrm{C}^{\mathrm{a}}$ & -11 & -16 & -21 & -27 & -19 \\
$\operatorname{Tan} \delta$ & 0.278 & 0.453 & 0.291 & 0.176 & 0.333 \\
\hline
\end{tabular}

Abbreviations: DMA, dynamic mechanical analysis; SPU, segmented polyurethane elastomer. ${ }^{\mathrm{a}} T_{\mathrm{G}}$ defined here as the position of the $\tan \delta$ peak at $1 \mathrm{~Hz} .{ }^{13}$

during heating, at $\sim 50{ }^{\circ} \mathrm{C}$. It should also be mentioned that in the case of $\mathrm{SPU}_{4}$ there appear mesophase structures, ${ }^{12,13}$ which are evidenced by a small endotherm maximum at about $220^{\circ} \mathrm{C}$.

\section{WAXS measurements}

Figure 8 shows WAXS scattering patterns of the SPU series from Table 1. As seen, the various materials display different degrees of crystallinity, as revealed by the presence of sharp diffraction peaks. $\mathrm{SPU}_{1}$ barely shows any evidence of crystalline reflections, and must be considered as almost but not completely amorphous. $\mathrm{SPU}_{2}, \mathrm{SPU}_{3}$ and $\mathrm{SPU}_{5}$ exhibit slightly higher crystallinities than $\mathrm{SPU}_{1}$, which is still

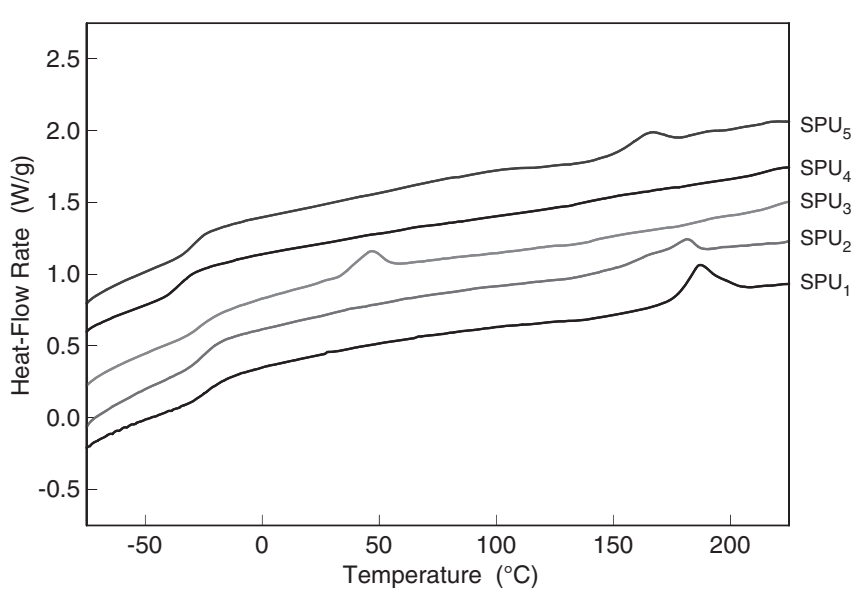

Figure 6 Differential scanning calorimetry curves for segmented polyurethane elastomers (SPUs) listed in Table 1, for a heating rate of $20 \mathrm{~K} \mathrm{~min}^{-1}$ : low-temperature region. ${ }^{13}$

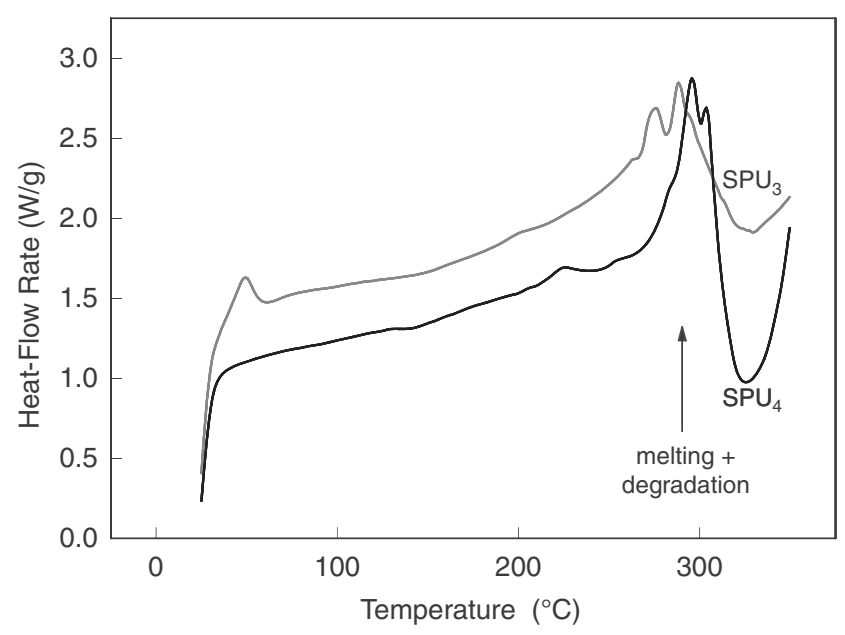

Figure 7 Differential scanning calorimetry curves for polymers $\mathrm{SPU}_{3}$ and $\mathrm{SPU}_{4}$ (Table 1), for a heating rate of $20 \mathrm{~K} \mathrm{~min}^{-1}$ : high-temperature region. $\mathrm{SPU}$, segmented polyurethane elastomer.

$<20 \%$. The sample $\mathrm{SPU}_{4}$ based on DBDI alone is the most crystalline sample and displays a crystallinity of $50 \%$.

\section{AFM results}

Normally, the surface of a sample fracture shows a relief composed of peaks of hard segments and crystal aggregates domains. The rupture occurs in the amorphous regions. Therefore, it is expected that such a surface contains more information about the sample morphology than the surface of free solidification or drying. AFM images were taken from different zones for each sample. Shown in Figure 9 are representative images of the freeze-fracture surfaces for the whole series of the materials $\left(\mathrm{SPU}_{1}\right.$ to $\left.\mathrm{SPU}_{5}\right)$.

The values depicted in Table 3 for the parameters $H_{\mathrm{a}}$ and $S_{\mathrm{q}}$ show some correlations between the morphology of the SPU and their chemical structure. Thus, as revealed by the $H_{\mathrm{a}}$ and $S_{\mathrm{q}}$ parameters, the corresponding roughness order $\mathrm{SPU}_{2}>\mathrm{SPU}_{3}>\mathrm{SPU}_{4}>$ $\mathrm{SPU}_{1} \approx \mathrm{SPU}_{5}$ indicates that the most uneven relief appears when the material is obtained by following the two-stage prepolymer polyaddition procedure. 


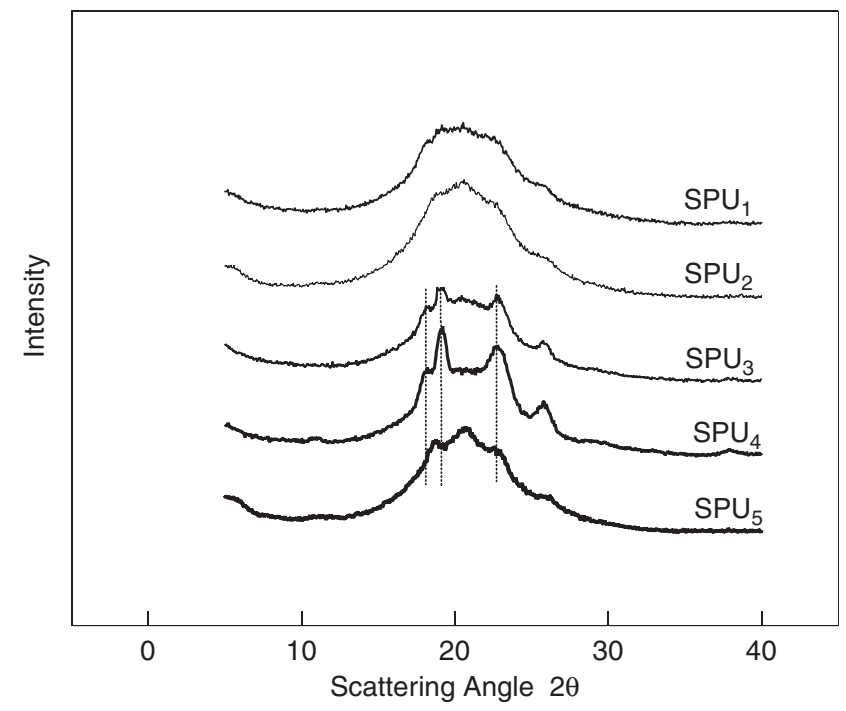

Figure 8 Wide-angle $\mathrm{X}$-ray diffractograms from materials listed in Table $1 .{ }^{13}$ SPU, segmented polyurethane elastomer.

A plausible explanation would be the following: when the macrodiol is first and completely reacted with one of the two diisocyanates (here denoted as $\mathrm{DI}_{1}$ ), the excess of $2 \mathrm{~mol}$ of $\mathrm{DI}_{1}$ to $1 \mathrm{~mol}$ of macrodiol in the first reaction step results in a prepolymer that mainly consists of macrodiol molecules with monoreacted $\mathrm{DI}_{1}$ ends. At the end of the process, when the rest of the reactants are added (that is, $3 \mathrm{~mol}$ of chain extender and $2 \mathrm{~mol}$ of the second diisocyanate (here denoted as $\left.\mathrm{DI}_{2}\right)$ ), a polymer with $-\left(\mathrm{DI}_{2}-\mathrm{CE}-\mathrm{DI}_{1}-\mathrm{MD}-\mathrm{DI}_{1}-\mathrm{CE}-\mathrm{DI}_{2}-\mathrm{CE}\right)-$ units should result (in which $\mathrm{CE}$ is the chain extender). This is the case with the polymers $\mathrm{SPU}_{2}$ and $\mathrm{SPU}_{3}$. The fact that the roughness is significantly higher for $\mathrm{SPU}_{2}$ than for $\mathrm{SPU}_{3}$ may be associated with crystallinity, which is promoted by the presence of DBDI and is absent in the materials based on the single diisocyanate MDI (Table 3). The difference in crystallinity associated with DBDI and MDI was previously evidenced and ascribed to the flexibility of the hard segments, which is characteristic to the DBDI segments and absent in the MDI hard segments. ${ }^{9}$

With regard to the roughness order, it is evident that the crosssections of the materials $\mathrm{SPU}_{4}, \mathrm{SPU}_{5}$ and $\mathrm{SPU}_{1}$ (in which the two diisocyanates are mixed together in a random manner through the one-stage prepolymer synthesis route) are smoother than those obtained by the two-stage prepolymer polyaddition procedures. This is not only due to crystallinity as long as this parameter is the largest for the material $\mathrm{SPU}_{4}$, but not in the case of polymer $\mathrm{SPU}_{2}$. Taking into account the morphology model of the hard segment phase dispersed into the soft segment phase, ${ }^{14}$ our assumption is that the domains of the soft segment crystals (if present) joined by hard segment matrices are small and dense in the SPUs obtained by the one-step prepolymer route, whereas they are bulky and rare in the SPUs obtained by the two-step prepolymer techniques. Such morphology is supported by the topographic three-dimensional and two-dimensional images in Figure 9 if, for example, the images of the samples $\mathrm{SPU}_{2}$ and $\mathrm{SPU}_{5}$ are compared with those of the samples $\mathrm{SPU}_{2}$ and $\mathrm{SPU}_{3}$, respectively.

It results that the different morphologies are related to the differences in the chain microstructure. Therefore, although the chains resulted from two-step prepolymer syntheses are predominantly built with $-\left(\mathrm{DI}_{2}-\mathrm{CE}-\mathrm{DI}_{1}-\mathrm{MD}-\mathrm{DI}_{1}-\mathrm{CE}-\mathrm{DI}_{2}-\mathrm{CE}\right)$ - units, the chains obtained from one-step prepolymer polyaddition processes are more heterogeneous because of the presence of amounts of other sequences such as -CE-DI-MD-DI-MD-DI- and -CE-DI-CE-DI-CE-DI-. Obviously, the polymer chain heterogeneity does not promote the orientation of the chains.

It is of interest to consider the NSH parameter given by the ratio of the average height, $H_{\mathrm{a}}$, to the RMS roughness, $S_{\mathrm{q}}$. Discussions regarding this parameter are absent in the literature. As shown in Table 3, the NSH data more or less follow the order of the $H_{\mathrm{a}}$ and $S_{\mathrm{q}}$ values; however, the differences between the materials are smaller. By correlating NSH with the characteristics of the surface relief, it observed that NSH increases not only with the roughness but also with the decrease in the relief uniformity. Comparing the samples $\mathrm{SPU}_{4}$ and $\mathrm{SPU}_{2}$, which show much different values for $H_{\mathrm{a}}$ and $S_{\mathrm{q}}$ but almost similar NSH values, it results that the relief of $\mathrm{SPU}_{2}$ is more uniform than that of $\mathrm{SPU}_{4}$.

\section{TENSILE TEST RESULTS}

The materials were subjected to a series of cyclic uniaxial tensile tests at room temperature and ambient humidity, designed to characterize features of their mechanical response relevant to their performance as thermoplastic elastomers, especially focusing on their stiffness (Table 4). The performance of SPUs as elastomers was assessed by means of a series of cyclic tensile tests, cycling between $300 \%$ elongation and zero load, using a constant nominal strain rate of magnitude $0.03 \mathrm{~s}^{-1}$. From these tests, the initial input strain energy density $E_{1 \mathrm{C}}$ was computed as the area under the first cycle loading curve of nominal stress versus nominal strain up to the elongation limit of $300 \%$. Similarly, recovered energy density $E_{1 \mathrm{R}}$ was computed as the area under the unloading curves for first cycle. From these two elasticity measures, the strain energy recovery on cycling (hysteresis) $E_{1 \mathrm{H}}$ was determined as previously described. ${ }^{11}$

There were observed significant differences between the materials obtained with single and mixed DI, caused by the mechanical contribution of the hard phase, as the matrix was formed for all SPUs from the same macrodiol (PEA) and same chain extender (EG).

The stress to produce a $300 \%$ nominal strain was higher in the case of material $\mathrm{SPU}_{1}$ obtained by a single-step prepolymer synthesis when both diisocyanates were included and reacted together in a random manner. Example tensile load/unload cycles at a 300\% elongation are shown in Figure 7 for the material $\mathrm{SPU}_{1}$ as compared with the materials obtained with single diisocyanates $\mathrm{SPU}_{4}$ (obtained with DBDI) and $\mathrm{SPU}_{5}$ (obtained with MDI), and in Figure 8 for the materials with mixed diisocyanates, $\mathrm{SPU}_{1}, \mathrm{SPU}_{2}$ and $\mathrm{SPU}_{3}$.

Of all, the lowest strain recovery was observed in the case of the material $\mathrm{PU}_{4}$ obtained from a single diisocyanate, in which the chain extender-diisocyanate couple was -(EG-DBDI) $)_{n}$, in which the hard segments were observed to crystallize.$^{5,7-9}$ For the SPU series depicted in Table 1 , the highest tensile strength $(46.8 \mathrm{MPa})$ and the lowest residual elongation (20\%) were observed for the material based on mixtures of diisocyanates included and reacted together in a random manner, $\mathrm{SPU}_{1}$, as shown in Table 4 (Figures 10 and 11).

As shown in Table 4, in particular, polymer $\mathrm{SPU}_{4}$ with DBDI hard segments showed higher stiffness and strength than the conventional MDI-based polymer $\mathrm{SPU}_{5}$, but with lower strain recovery and strain energy recovery on cycling-a primary consideration for elastomers. Both features of the response were attributed to differences in hardphase plastic flow stress, resulting from crystallinity in the DBDI phase, ${ }^{11}$ absent in MDI.

The polymer $\mathrm{SPU}_{1}$ with randomly mixed MDI/DBDI hard phase, however, showed advantages of increased tensile strength and low residual elongation, plus increased strain recovery, as revealed by the 

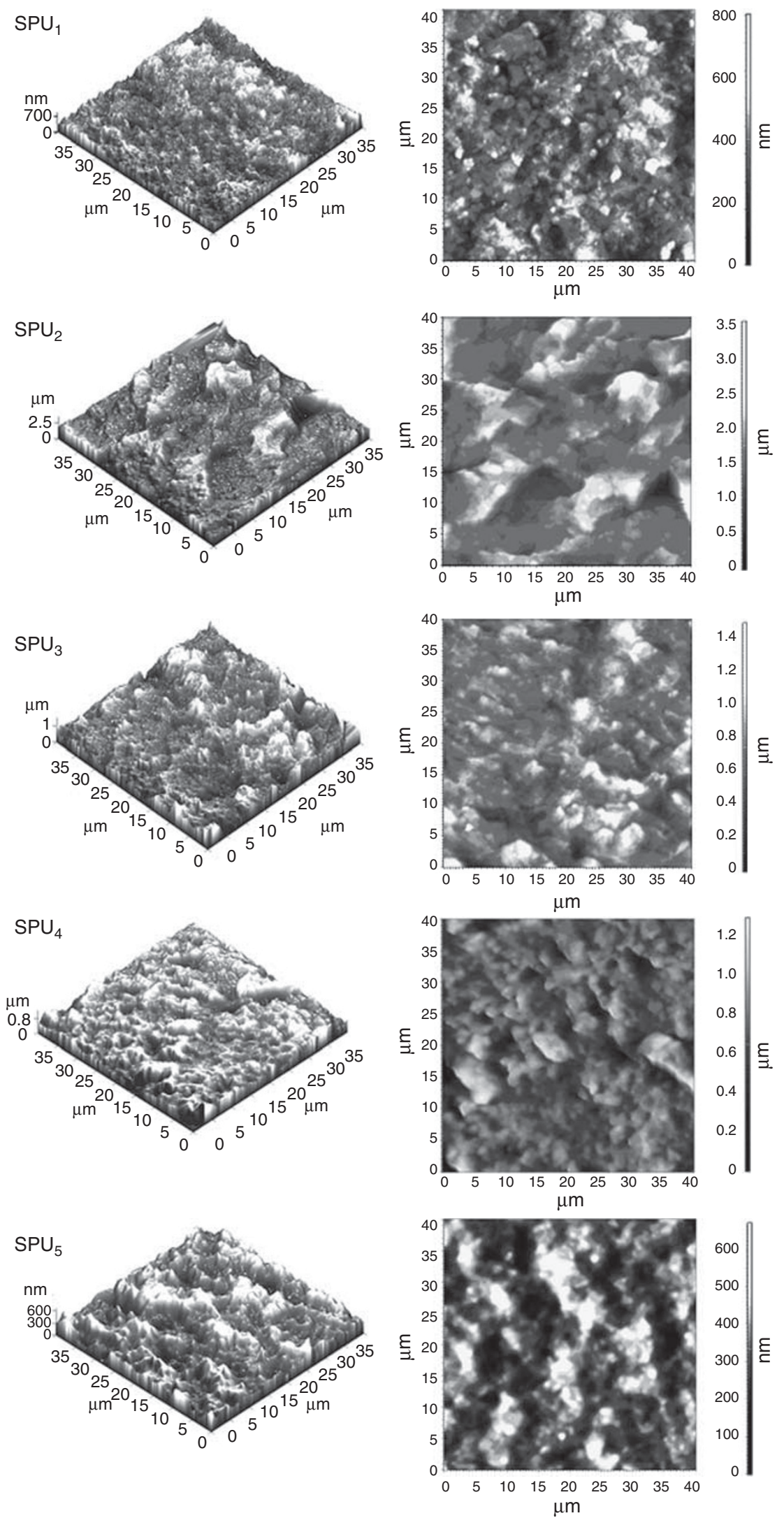

Figure 9 Tapping mode atomic force microscopy topographic three-dimensional and two-dimensional images for freeze-fracture surfaces for materials listed in Table 1. SPU, segmented polyurethane elastomer. 
lowest hysteresis value in Table 4, compared with the conventional polymer $\mathrm{SPU}_{5}$, thus offering improvements in all these properties.

\section{CONCLUSIONS}

A range of segmented copolyurethane polymers was synthesized, in which the hard segment consisted of the flexible isocyanate DBDI, the conventional rigid isocyanate MDI or mixtures of these two isocyanates. Chain extension was achieved by using a low molecular weight diol, EG. SPUs were prepared with no excess of NCO groups, yielding isocyanic index $\mathrm{I}=100$. Changes induced by varying the type and the number of isocyanates were followed. DBDI has a variable geometry that allows crystallinity to develop, and leads to an increase in mechanical properties (tensile stress, tensile strength, hardness and strain energy); the residual elongation is also markedly increased.

Crystallinity, as revealed by WAXS measurements, was strongly reduced when DBDI was mixed with MDI. The AFM images of the fracture surfaces revealed that the SPU materials obtained by the two-step prepolymers routes showed a more uneven relief than those prepared by the one-step prepolymer route. In addition, DBDI increased this difference but led to more uniform relief forms than MDI.

The highest tensile strengths were obtained when the two diisocyanates were introduced simultaneously in the prepolymer synthesis stage ( $\mathrm{SPU}_{1}$ type). Inelastic effects were more pronounced when the hard segment crystallized; that is, when DBDI alone was used in the material synthesis $\left(\mathrm{SPU}_{4}\right.$ type), in which the stiffness, hysteresis and residual elongation were found to be all increased relative to the corresponding MDI-based materials.

The differences between DBDI and MDI were attributed to the greater flexibility of DBDI, allowing a higher tendency to self-associate by hydrogen bonding. Inelasticity (residual strain, hysteresis) decreased in the case of the material with mixtures of diisocyanates.

The general improvement in properties with DBDI was retained when both diisocyanates were included, especially when reacted together in a random manner, rather than sequentially, in the

Table 3 Surface roughness parameters from AFM height images

\begin{tabular}{|c|c|c|c|c|c|}
\hline \multirow{2}{*}{$\begin{array}{l}\text { Sample identification } \\
\text { Code }\end{array}$} & \multirow{2}{*}{$\begin{array}{l}\text { Crystallinity index } \\
\text { Composition }\end{array}$} & \multicolumn{4}{|c|}{ Surface roughness parameters } \\
\hline & & $\mathrm{Cl}(\%)$ & $\mathrm{H}_{a}(n m)$ & $\mathrm{S}_{q}(n m)$ & $\mathrm{NSH}\left(\mathrm{H}_{a} / \mathrm{S}_{q}\right.$ \\
\hline $\mathrm{SPU}_{1}$ & EG-PEA-(DBDI-MDI) & $<20$ & 399.4 & 116.1 & 3.44 \\
\hline $\mathrm{SPU}_{2}$ & EG-(PEA-DBDI)-MDI & $>20$ & 1617.7 & 368.9 & 4.38 \\
\hline $\mathrm{SPU}_{3}$ & EG-(PEA-MDI)-DBDI & $>30$ & 717.4 & 191.8 & 3.74 \\
\hline $\mathrm{SPU}_{4}$ & EG-PEA-DBDI & $\sim 50$ & 669.3 & 153.9 & 4.35 \\
\hline $\mathrm{SPU}_{5}$ & EG-PEA-MDI & $>25$ & 320.1 & 101.6 & 3.15 \\
\hline
\end{tabular}

Abbreviations: AFM, atomic force microscopy; $\mathrm{Cl}$, confidence interval; DBDI, 4,4-dibenzyl diisocyanate; EG, ethylene glycol; MDI, 4,4-diphenylmethane diisocyanate; PEA, polyethylene adipate; SPU, segmented polyurethane elastomer. prepolymer stage. Optimum mechanical response was obtained with randomly mixed MDI/DBDI hard phase.

This eliminates the major inconvenience derived from the high permanent deformability, for example, high residual elongations and leads also practically to the disappearance of crystallinity otherwise undesired for an elastomer. With the $\mathrm{SPU}_{1}$ type, especially, the greater tensile strength was combined with the elastic recovery of more conventional polyurethane.

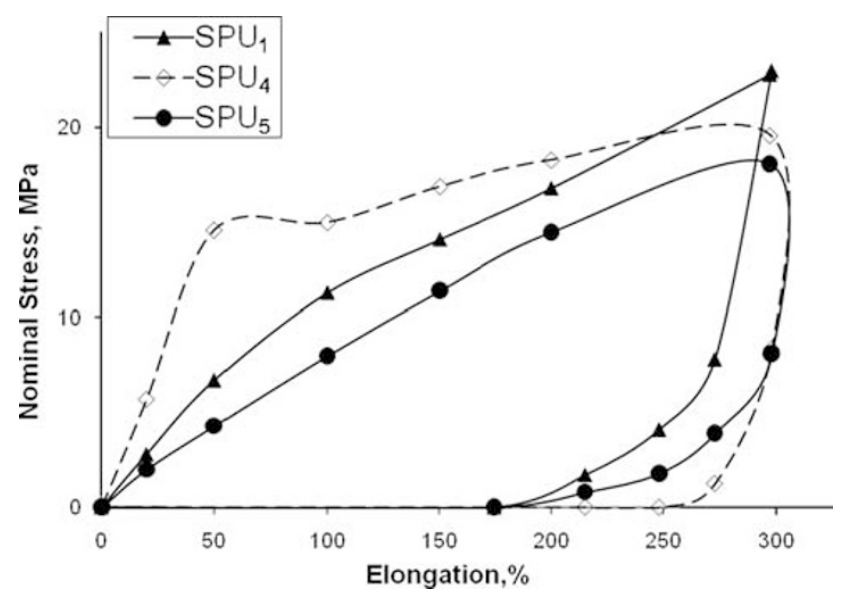

Figure 10 Examples first tensile load/unload cycles for materials $\mathrm{SPU}_{1}$, $\mathrm{SPU}_{4}$ and $\mathrm{SPU}_{5}$, at strain rate $0.03 \mathrm{~s}^{-1}$. SPU, segmented polyurethane elastomer.

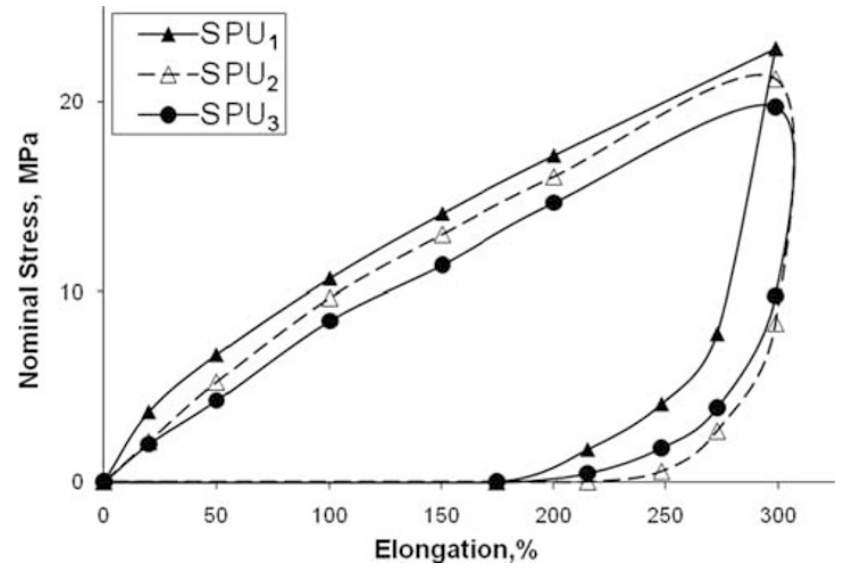

Figure 11 Examples first tensile load/unload cycles, for materials $\mathrm{SPU}_{1}$, $\mathrm{SPU}_{2}$ and $\mathrm{SPU}_{3}$ obtained with mixtures of diisocyanates. SPU, segmented polyurethane elastomer.

Table 4 Tensile test results for the family of materials listed in Table

\begin{tabular}{|c|c|c|c|c|c|c|}
\hline $\begin{array}{l}\text { SPU } \\
\text { type }\end{array}$ & $\begin{array}{l}\text { Nominal Stress at } \\
100 \% \text { strain }(\mathrm{MPa})\end{array}$ & $\begin{array}{l}\text { Nominal Stress at } \\
300 \% \text { strain (MPa) }\end{array}$ & $\begin{array}{c}\text { Strength } \\
\text { stress (MPa) }\end{array}$ & $\begin{array}{c}\text { Elongation at } \\
\text { break, (\%) }\end{array}$ & $\begin{array}{c}\text { Residual } \\
\text { elongation (\%) }\end{array}$ & $\begin{array}{c}\text { Hysteresis } \\
\text { (\%) }\end{array}$ \\
\hline $\mathrm{SPU}_{1}$ & 11.2 & 22.8 & 46.8 & 450 & 20 & 61.2 \\
\hline $\mathrm{SPU}_{2}$ & 9.7 & 19.7 & 38.6 & 375 & 50 & 74.6 \\
\hline $\mathrm{SPU}_{3}$ & 8.9 & 18.2 & 30.3 & 350 & 40 & 71.8 \\
\hline $\mathrm{SPU}_{4}$ & 15.8 & 18.2 & 43.7 & 525 & 155 & 81.4 \\
\hline $\mathrm{SPU}_{5}$ & 8.7 & 16.6 & 38.6 & 425 & 35 & 68.6 \\
\hline
\end{tabular}

Abbreviation: SPU, segmented polyurethane elastomer. 
1 Estes, G. M., Seymour, R. W. \& Cooper, S. L. Infrared studies of segmented polyurethane elastomers. II. Infrared dichroism. Macromolecules 4, 452-457 (1971).

2 Petrovic, Z. S. \& Ferguson, J. Polyurethane elastomers. Prog. Polym. Sci. 16, 695-836 (1991).

3 Russo, R. \& Thomas, E. C. Phase separation in linear and cross-linked polyurethanes. J. Macromol. Sci. Phys. B22(4), 553-575 (1983).

4 Pandya, M. V., Deshpande, D. D. \& Hundiwale, D. G. Effect of diisocyanate structure on viscoelastic, thermal, mechanical and electrical properties of cast polyurethanes. J. Appl. Polym. Sci. 32, 4959-4966 (1986).

5 Hesketh, T. R., Van Bogart, J. V. C. \& Cooper, S. L. Differential scanning calorimetry analysis of morphological changes in segmented elastomers. Polym. Eng. Sci. 20, 190 (1980).

6 Zdrahala, R. J., Gerkin, R. M., Hager, S. L. \& Critchfield, I. E. Polyester based thermoplastic polyurethanes. I Effect of hard segment content. J. Appl. Polym. Sci. 24, 2041 (1979).

7 Qi, J. J. \& Boyce, M. C. Stress-strain behavior of thermoplastic polyurethanes. Mech. Mater. 37, 817-839 (2005).
8 Prisacariu, C. \& Scortanu, E. Infrared dichroic studies of phase separation and orientation of dibenzyl hard segments in polyurethanes. High Perform. Polym. 20, 117-125 (2008)

9 Buckley, C. P., Prisacariu, C. \& Martin, C. M. Elasticity and inelasticity of thermoplastic polyurethane elastomers: sensitivity to chemical and physical structure. Polymer 51, 3213-3224 (2010).

10 Buckley, C. P., Prisacariu, C. \& Caraculacu, A. Novel triol-crosslinked polyurethanes and their thermorheological characterization as shape-memory materials. Polymer 48, 1388-1396 (2007).

11 Prisacariu, C., Buckley, C. P. \& Caraculacu, A. A. Mechanical response of dibenzylbased polyurethanes with diol chain extension. Polymer 46, 3884-3894 (2005).

12 Prisacariu, C., Olley, R. H., Caraculacu, A., Bassett, D. C. \& Martin, C. M. The effect of hard segment in copolyurethane elastomers obtained by using simultaneously two types of diisocyanates. Polymer 44, 5407-5421 (2003).

13 Prisacariu, C. \& Scortanu, E. (ed. R.A. Meyers), ISBN: 978-04-7002-731-8, (a9150), 1-24, (John Wiley \& Sons. Ltd, (2010).

14 Christenson, B. E. M., Anderson, J. M., Hiltner, A. \& Baer, E. Relationship between nanoscale deformation processes and elastic behavior of polyurethane elastomers. Polymer 46, 11744-11754 (2005). 